Gut, 1975, 16, 937-942

\title{
Gallbladder function, cholesterol stones, and bile composition
}

\author{
G. ANTSAKLiS, M. R. LEWIN ${ }^{1}$, D. JUNE SUTOR, A. G. A. COWIE, AND \\ C. G. CLARK
}

From the Department of Surgery, University College Hospital Medical School, London, and the Department of Chemistry, University College, London

SUMMARY Gallbladder bile obtained at operation from five patients with no symptoms of biliary disease was undersaturated with cholesterol in every case. However, gallbladder bile from patients with stones composed of $97-100 \%$ crystalline cholesterol was on average just saturated with cholesterol when the gallbladder was functioning and undersaturated when it was not. Regardless of gallbladder function, the patients with stones had on average significantly more cholesterol in their bile than the control group, but the differences between the mean composition of bile from functioning and non-functioning gallbladders were not significant. Common duct bile from patients with non-functioning and functioning gallbladders was on average supersaturated with cholesterol, but there was significantly more bile salt and significantly less cholesterol in the bile from patients with non-functioning gallbladders. Only in the case of patients with functioning gallbladders did the mean composition of the common duct and gallbladder biles differ significantly. The former contained significantly more cholesterol and less bile salt than the latter. It is suggested that patients with non-functioning gallbladders may be 'autocholecystectomised' with the duct bile reverting to a more 'normal' composition.

Small and Rapo (1970) and Vlahcevic et al. (1970) showed that hepatic bile in their group of patients undergoing cholecystectomy for cholesterol gallstones was always supersaturated with cholesterol. Other workers, however, have sometimes found hepatic bile of normal composition in similar stoneformers under the same conditions (Mackay et al., 1972; Smallwood et al., 1972; Cahlin et al., 1973). Such different results could reflect variations in the methods used in measuring gallstone and bile composition, or, represent real differences in the groups of patients studied, since production of a supersaturated bile by the liver may not always be the primary abnormality in cholesterol gallstone formation.

In order to understand gallstone formation, bile composition must be known in different circumstances. Few (Bell et al., 1973; Cahlin et al., 1973) studies have attempted to relate bile composition and gallbladder function, so we have investigated this in patients with pure cholesterol stones (97$100 \%$ crystalline cholesterol).

\footnotetext{
'Address for correspondence: M. R. L., Department of Surgery, University College Hospital Medical School, University Street, London WC1.

Received for publication 14 October 1975
}

\section{Methods}

Thirty-two patients undergoing surgery for cholesterol gallstones formed the basis of this study. Preoperatively, liver function tests and serum cholesterol estimations were performed on all patients. Gallbladder function was assessed by oral cholecystography. At operation the gallbladder was aspirated completely to avoid stratification errors (Tera, 1960), having first clamped the cystic duct to minimize mixing of gallbladder bile with that from the common duct. Thereafter, the cystic duct was divided and bile obtained by cannulation of the common duct before the performance of operative cholangiography. Of $\mathbf{3 2}$ gallbladders aspirated, four contained insufficient bile for analysis, and another five contained white bile and these were excluded from this study. Bile from the common bile duct was not obtained from 18 patients for technical reasons. After cholecystectomy, stones were removed from the gallbladder for subsequent analysis.

At the conclusion of the operation, bile samples were stored at $-14{ }^{\circ} \mathrm{C}$. Before chemical analysis, all the samples were thawed slowly to room temperature and vigorously shaken. Total bile salts were estimated by the steroid dehydrogenase method 
of Talalay (1960) as modified by Admirand and Small (1968). Cholesterol concentrations were estimated by the methods described by Babson $e t$ al. (1962) and Leffler and McDougald (1963). Phospholipids were estimated as inorganic phosphorus (Fiske and Subbarrow, 1925), after extraction of the bile with chloroform and methanol, and digestion of the lipids with sulphuric acid. The results were expressed as percentages of the total molar concentration of cholesterol, phospholipid, and bile salts, and plotted on a three-component diagram showing the micellar zone of cholesterol solubility as determined by Admirand and Small (1968).

The gallstones were soaked in formaldehyde for 24 hours, washed well with water and air dried. They were analysed by the $x$-ray powder method using the techniques described by Sutor and Wooley $(1969,1971)$.

Phospholipid and bile salt results were statistically analysed by multiple comparisons at the $5 \%$ level
(Scheffé, 1959), while the cholesterol results were analysed using Welch's approximate $t$ test on the transformed data (Scheffé, 1970).

Bile was obtained only from the gallbladders of five patient undergoing operations for other conditions-namely, duodenal ulceration, Crohn's disease, carcinoma of the stomach, and pancreatic disease (two cases). None of these patients had symptoms of biliary disease.

\section{Results}

No patient had any biochemical evidence of altered or impaired liver function or an abnormal serum cholesterol.

CONTROLS

The mean molar percentage composition of gallbladder bile from the five control subjects is given in Table 1 together with other results from the

\begin{tabular}{|c|c|c|c|c|c|}
\hline \multirow[t]{2}{*}{ Author } & \multirow[t]{2}{*}{ No. } & \multirow[t]{2}{*}{ Origin of sample } & \multicolumn{3}{|c|}{ Percentage molar lipid composition (mean $\pm S E M$ ) } \\
\hline & & & Cholesterol & Phospholipids & \\
\hline Simmons et al. (1972) & 10 & Duodenal aspirate & $\begin{array}{r}8.0 \\
\pm 1.2\end{array}$ & $\begin{array}{r}14.0 \\
\pm \quad 2.5\end{array}$ & $\begin{array}{r}78.0 \\
+\quad 3.4\end{array}$ \\
\hline Mackay et al. (1972) & 21 & Duodenal aspirate & $\begin{array}{r}5.1 \\
\pm 0.4\end{array}$ & $\begin{array}{r}18: 7 \\
\pm \quad 1.5\end{array}$ & $\begin{array}{r}76.1 \\
\pm \quad 1.7\end{array}$ \\
\hline Heller and Bouchier* (1973) & 12 & Gallbladder bile & $\begin{array}{r}6.9 \\
+1.0\end{array}$ & $\begin{array}{r}17.6 \\
\pm \quad 0.8\end{array}$ & $\begin{array}{r}75.3 \\
\pm \quad 1.6\end{array}$ \\
\hline Vlahcevic et al. (1972) & 7 & Duodenal aspirate & $\begin{array}{r}7.9 \\
\pm 1.0\end{array}$ & $\begin{array}{r}23.2 \\
\pm \quad 3.4\end{array}$ & $\begin{array}{r}68.9 \\
\pm \quad 3.7\end{array}$ \\
\hline
\end{tabular}

Table 1 Percentage molar lipid composition in control subjects

*SEM calculated from original data.

\begin{tabular}{|c|c|c|c|c|c|c|c|c|c|}
\hline \multirow[t]{3}{*}{ Authors } & \multirow{3}{*}{$\begin{array}{l}\text { Gallbladder } \\
\text { function }\end{array}$} & \multirow[t]{3}{*}{ No. } & \multicolumn{7}{|c|}{ Percentage molar lipid composition (mean $\pm S E M$ ) } \\
\hline & & & \multicolumn{3}{|c|}{ Gallbladder bile } & \multirow[b]{2}{*}{ No. } & \multicolumn{3}{|c|}{ Common duct bile } \\
\hline & & & Cholesterol & Phospholipids & Bile salts & & Cholesterol & Phospholipids & Bile salts \\
\hline Present study & Yes & 15 & $\begin{array}{r}9 \cdot 2 \\
+\quad 0.7\end{array}$ & $\begin{array}{r}14 \cdot 3 \\
+\quad 2 \cdot 2\end{array}$ & $\begin{array}{r}76 \cdot 4 \\
+\quad 2 \cdot 4\end{array}$ & 5 & $\begin{array}{r}22.9 \\
+\quad 5.6\end{array}$ & $\begin{array}{r}13.9 \\
+\quad 3.1\end{array}$ & $\begin{array}{r}63.2 \\
+\quad 4.9\end{array}$ \\
\hline Present study & No & 8 & $\begin{array}{r}8.4 \\
+1.5\end{array}$ & $\begin{array}{r}16.2 \\
+\quad 2.9\end{array}$ & $\begin{array}{r}75.4 \\
+\quad 3.8\end{array}$ & 9 & $\begin{array}{r}10.7 \\
+\quad 1.2\end{array}$ & $\begin{array}{r}11.7 \\
+\quad 2.6\end{array}$ & $\begin{array}{r}77.6 \\
+\quad 3.3\end{array}$ \\
\hline Vlahcevic et al.* (1970) & $\begin{array}{l}\text { Not } \\
\text { specified }\end{array}$ & 14 & $\begin{array}{r}12.5 \\
\pm \quad 1.1\end{array}$ & $\begin{array}{r}23.8 \\
+\quad 1.3\end{array}$ & $\begin{array}{r}63.7 \\
+\quad 1.9\end{array}$ & 11 & $\begin{array}{r}14.5 \\
\pm \quad 1.5\end{array}$ & $\begin{array}{r}23.9 \\
+\quad 1.6\end{array}$ & $\begin{array}{r}61.6 \\
+\quad 2.4\end{array}$ \\
\hline Small and Rapo (1970) & Yes & 18 & $\begin{array}{r}8.6 \\
+0.5\end{array}$ & $\begin{array}{r}19.7 \\
\pm \quad 0.4\end{array}$ & $\begin{array}{r}71.6 \\
\pm \quad 0.6\end{array}$ & 21 & $\begin{array}{r}16.6 \\
\pm \quad 1.2\end{array}$ & $\begin{array}{r}25.1 \\
\pm \quad 1.5\end{array}$ & $\begin{array}{r}58.2 \\
\pm \quad 2.5\end{array}$ \\
\hline Mackay et al. (1972) & Yes & 17 & $\begin{array}{r}7 \cdot 2 \\
\pm \quad 0.5\end{array}$ & $\begin{array}{r}18.6 \\
+\quad 1.5\end{array}$ & $\begin{array}{r}74.2 \\
\pm \quad 1.8\end{array}$ & 17 & $\begin{array}{r}9.1 \\
\pm \quad 0.7\end{array}$ & $\begin{array}{r}21.8 \\
\pm \quad 1.7\end{array}$ & $\begin{array}{r}69.1 \\
\pm \quad 2.2\end{array}$ \\
\hline Vlahcevic et al. (1972) & Yes & 8 & $\begin{array}{r}14.9 \\
\pm \quad 3.3\end{array}$ & $\begin{array}{r}25.8 \\
\pm \quad 2.9\end{array}$ & $\begin{array}{r}59.3 \\
\pm \quad 4.5\end{array}$ & 8 & $\begin{array}{r}15.5 \\
\pm \quad 3.8\end{array}$ & $\begin{array}{r}25.4 \\
\pm \quad 4.7\end{array}$ & $\begin{array}{r}59.1 \\
\pm \quad 6.5\end{array}$ \\
\hline Simmons et al. (1972) & Yes & & - & - & - & 23 & $\begin{array}{r}13.0 \\
\pm \quad 1.1\end{array}$ & $\begin{array}{r}14.0 \\
\pm \quad 1.0\end{array}$ & $\begin{array}{r}73.0 \\
\pm \quad 1.3\end{array}$ \\
\hline Heller and Bouchier* (1973) & Yes & 16 & $\begin{array}{r}8.6 \\
\pm 1.0\end{array}$ & $\begin{array}{r}17.6 \\
\pm \quad 1.5\end{array}$ & $\begin{array}{r}73.7 \\
\pm \quad 1.9\end{array}$ & - & - & - & - \\
\hline
\end{tabular}

Table 2 Percentage molar lipid composition in gallbladder and common duct bile of cholesterol stone-formers *SEM calculated from original data. 


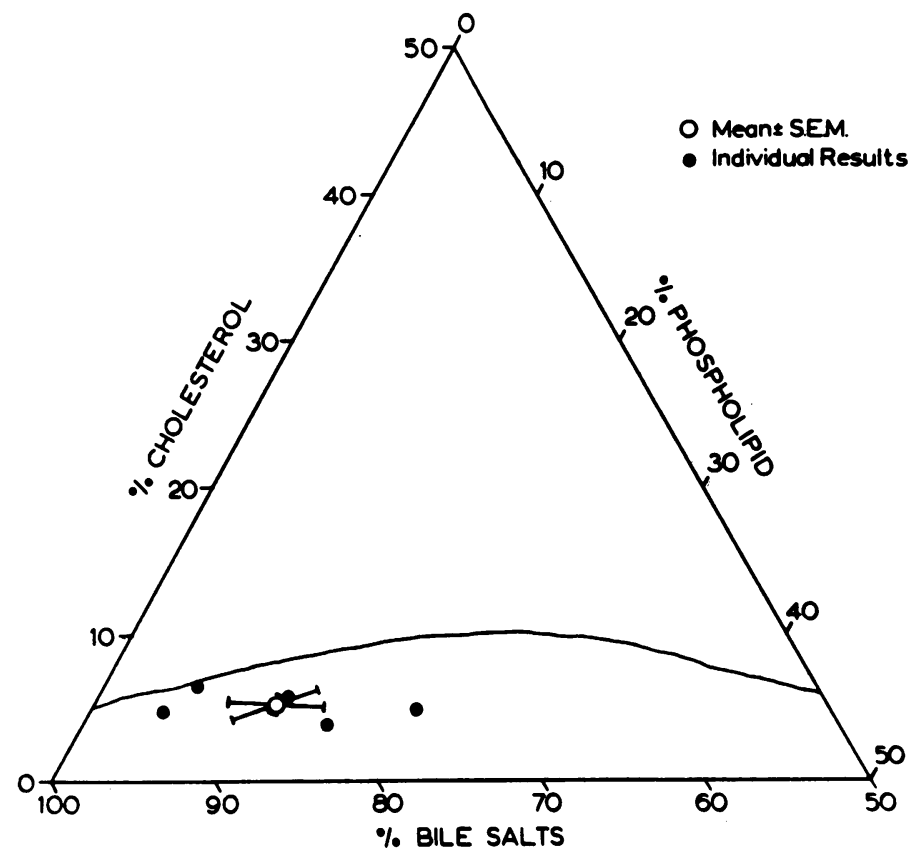

Fig. 1 Mean $\pm S E M$ and individual results for biliary lipid composition in gallbladder bile from five control subjects

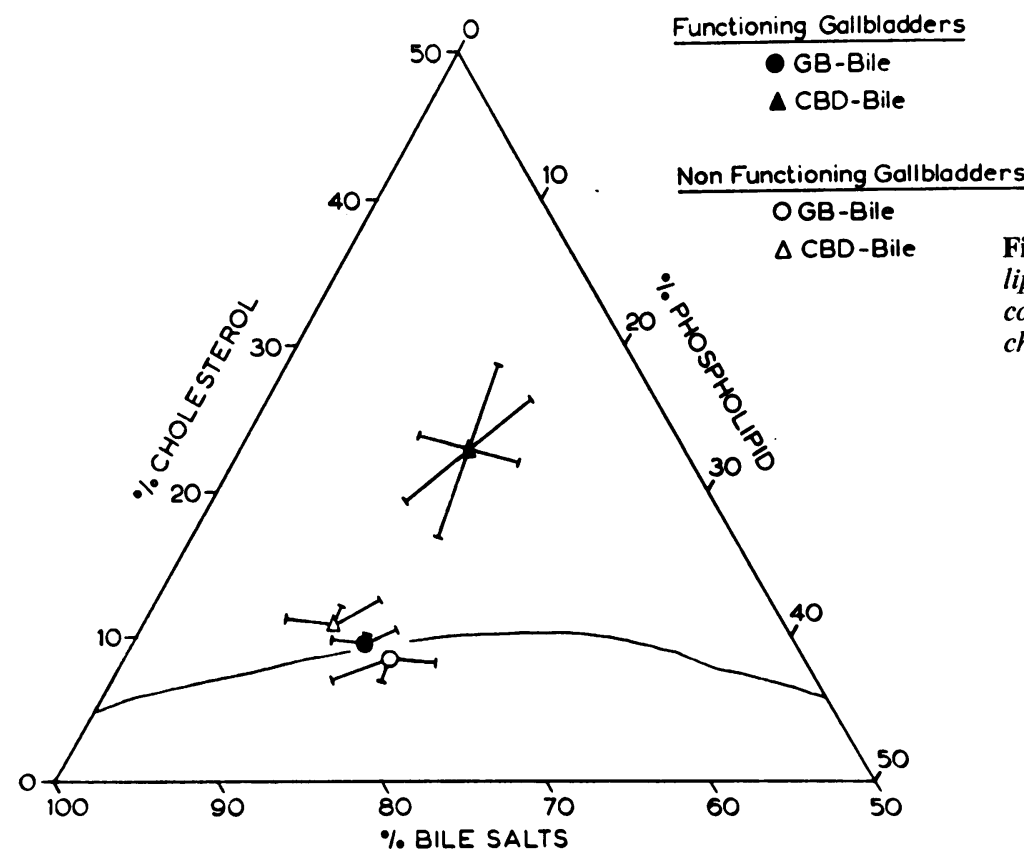

Fig. 2 Mean $\pm S E M$ for biliary lipid composition in gallbladder and common duct bile from patients with cholesterol gallstones

literature. Only one of these refers to bile obtained by the same method, the remainder being an analysis of duodenal aspirate. The individual results are plotted in Fig. 1 together with the mean and one micellar zone representing the composition of solutions undersaturated with respect to cholesterol. standard error. All of these points were within the The mean molar percentages for the three main 
biliary lipids in gallbladder and common duct bile for patients with functioning and non-functioning gallbladders are given in Table 2 together with some other published results. Our mean values with one standard error are plotted in Fig. 2. The points representing the mean composition of the common duct biles from patients with either functioning or non-functioning gallbladders fell outside the micellar zone, the latter point lying closer to the boundary. Bile from functioning gallbladders had a mean value which was on the boundary of the micellar zone and was thus just saturated with cholesterol, while that from non-functioning gallbladders had a mean composition represented by a point lying just within the micellar zone.

There was, however, considerable variation in the individual values. In the group with functioning gallbladders, the composition of $60 \%$ gallbladder biles and $100 \%$ common duct biles fell outside the micellar zone, while, in the group with non-functioning gallbladders, the composition of $50 \%$ gallbladder biles and $78 \%$ common duct biles were outside this area.

Table 3 shows the statistical significance in a comparison of the mean molar percentages of the three main biliary lipids. There was significantly more cholesterol in the gallbladder bile of stoneformers than in that of the controls regardless of gallbladder function $(P<0.001$ for patients with functioning and $P<0.05$ for those with nonfunctioning gallbladders). Comparing the bile from the common duct and the bile from the gallbladder in stone-formers with functioning gallbladders, there was significantly more cholesterol $(P<0.01)$

\begin{tabular}{|c|c|c|c|}
\hline \multirow[t]{2}{*}{ Compared groups } & \multicolumn{3}{|c|}{ Level of significance } \\
\hline & Cholesterol & $\begin{array}{l}\text { Phospho- } \\
\text { lipids }\end{array}$ & Bile salts \\
\hline $\begin{array}{l}\text { Control, GB-bile } \\
\text { vs } \\
\text { Functioning GB, GB-bile } \\
\text { Control, GB-bile }\end{array}$ & $P<0.001$ & NS & NS \\
\hline $\begin{array}{l}\text { vs } \\
\text { Non-functioning GB, GB-bile } \\
\text { Functioning GB, GB-bile }\end{array}$ & $P<0.05$ & NS & NS \\
\hline $\begin{array}{l}\text { vs } \\
\text { Functioning GB, CBD-bile } \\
\text { Non-functioning GB, GB-bile }\end{array}$ & $P<0.01$ & NS & $P<0.05$ \\
\hline $\begin{array}{l}\text { vs } \\
\text { Non-functioning GB, CBD-bile } \\
\text { Functioning GB, CBD-bile }\end{array}$ & NS & NS & NS \\
\hline $\begin{array}{l}\text { vs } \\
\text { Non-functioning GB, CBD-bile } \\
\text { Functioning GB, GB-bile }\end{array}$ & $P<0.05$ & NS & $P<0.05$ \\
\hline $\begin{array}{c}\text { vs } \\
\text { Non-functioning GB, GB-bile }\end{array}$ & NS & NS & NS \\
\hline
\end{tabular}

Table 3 Statistical testing between individual groups GB: gall bladder. CBD: common bile duct. and less bile salt $(P<0.05)$ in the common duct bile. Similarly, there was significantly more cholesterol $(P<0.05)$ and less bile salt $(P<0.05)$ in the common duct bile of stone-formers with functioning gallbladders as compared with common duct bile from patients with non-functioning gallbladders.

\section{Discussion}

This study shows that the composition of the common duct bile in patients with cholesterol gallstones is potentially lithogenic, as is the composition of the gallbladder bile of those patients whose gallbladder is functioning. However, if the gallbladder is nonfunctioning, the bile contained within it is more 'normal'. When points representing the molar ratios of the lipids in these biles are plotted on triangular coordinates, only the biles from the gallbladders of patients with non-functioning gallbladders fall within the micellar zone of cholesterol solubility. Despite considerable variation in individual cases, it is evident from our results that the difference chiefly responsible for this abnormality is a relative increase in the proportion of cholesterol and $a$ fall in the proportion of bile salt from the more normal levels seen in the controls. The molar ratios seen in this series for control patients are similar to those reported by others (Table 1), although there is a somewhat higher proportion of bile salt and lower proportion of phospholipid. However, the analyses in other series were performed chiefly on bile obtained by duodenal aspiration and are not strictly comparable. Table 2 shows that the biles from patients with cholesterol stones also have rather more bile salt and rather less phospholipid but otherwise compare well in most circumstances with bile compositions reported by others. The striking difference is the considerable increase in the cholesterol content of the bile from the common duct in our patients with functioning gallbladders. This finding is unlikely to be due to differences in methodology, since the analyses compare well in other circumstances. However, it is possible that cholesterol crystals may have been present in the bile from the common duct of patients with functioning gallbladders and not filtered before analysis. Van der Linden and Nakayama (1974) have shown that an excess of crystals may be present in the hepatic bile of such patients compared with patients whose gallbladder is not functioning.

In patients forming cholesterol gallstones, the cholesterol content of gallbladder bile is significantly greater than normal controls whether the gallbladder is functioning $(P<0.001)$ or non-functioning $(\mathrm{P}<0.05)$. Normal common duct bile dould not be obtained. Common duct bile from patients with 
functioning gallbladders contained significantly more cholesterol than the gallbladder bile $(P<0.01)$, but no such difference occurred in patients with non-functioning gallbladders (Table 3). These statistical differences, however, do not necessarily indicate the lithogenic potential of bile. It is only on consideration of the phase diagrams (Figs. 1 and 2), that it is evident that the most grossly lithogenic bile comes from the common duct in patients with functioning gallbladders. Since all patients had virtually pure cholesterol stones-and can therefore be presumed to be a population virtually with the same defect of bile composition-the conclusion must be that progressive deterioration in gallbladder function has the effect of reducing the lithogenic potential of common duct bile.

Admirand and Small (1968) suggested that the lithogenic changes in gallbladder bile composition could be detected in all cases, but others have been unable to confirm this (Smallwood et al., 1972; Heller and Bouchier, 1973). In this series only $60 \%$ of the gallbladder biles tested were potentially lithogenic, although $78 \%$ of the common duct biles when the gallbladder was non-functioning and $100 \%$ of the common duct biles when the gallbladder was functioning had molar ratios which could be plotted above the micellar line. These findings do, however, support the view that the primary biochemical abnormality occurs during the hepatic production of bile (Small and Rapo, 1970; Vlahcevic et al., 1970). Mackay et al. (1972), while supporting this view, point out that there must be other factors of importance since, although most abnormal biles contain more cholesterol and less bile salt, many have a composition still within the micellar zone.

Malagelada et al. (1973) showed that cholecystectomy, which changes the dynamics of the enterohepatic circulation from an intermittent process to a continuous one, results in a 24 hour output of bile which exceeds that which occurred preoperatively. This was disputed by Adler et al. (1974) who reported no change in secretion rates but their study was confined to a very small group of American Indians. Support for Malagelada's view came from Shaffer et al. (1972) who reported that interference with the enterohepatic circulation resulted in a fourfold increase in bile salt synthesis. The importance of the rate of bile salt secretion was shown recently by Scherstén et al. (1974) who showed that a minimum rate of secretion existed bilow which the bile became saturated with cholesterol. Fasting is known to affect bile composition in Rhesus monkeys (Redinger et al., 1971), although the bile never becomes oversaturated, and in man (Metzger et al., 1973), in whom the bile becomes more lithogenic. This may be a function of the fall in bile salt secretion rate or a rise in cholesterol. After cholecystectomy, the composition of common duct bile becomes more normal (Nilsson and Scherstén, 1969; Small and Rapo, 1970; Scherstén et al., 1971; Simmons et al., 1972) and this is probably a result of the change in enterohepatic circulation dynamics. Recently, Nakayama and Van der Linden (1974) have again reported this finding and in their cases the gallbladder bile at operation was not oversaturated, while the common duct bile was. They suggested that preoperative fasting might account for this difference.

Recently, Pederson et al. (1974) reported the effect of small doses of chenodeoxycholate given to four patients with radiolucent gallstones and functioning gallbladders. It was shown that there was on average a $40 \%$ reduction in the input of cholesterol into the rapidly miscible pool'. If this effect of bile salt on cholesterol metabolism is confirmed, it might explain the findings in the present series of a lower cholesterol level in bile if the gallbladder is non-functioning and the findings of a 'normalisation' of bile composition as reported by others after cholecystectomy.

We thank Mr I. Robertson, MRC Statistics Unit, for analysing the data, and the Medical Research Council for financial assistance.

\section{References}

Adler, R. D., Metzger, A. L., and Grundy, S. M. (1974). Biliary lipid secretion before and after cholecystectomy in American Indians with cholesterol gallstones. Gastroenterology, 66, 1212-1217.

Admirand, W. H., and Small, D. M. (1968). The physicochemical basis of cholesterol gallstone formation in man. Journal of clinical Investigation, 47, 1043-1052.

Babson, A. L., Shapiro, P. O., and Phillips, G. E. (1962). A new assay for cholesterol and cholesterol esters in serum which is not affected by bilirubin. Clinica et Chimica Acta, 7, 800-804.

Bell, G. D., Sutor, D. J., and Dowling, R. H. (1973). Relationship between bile and gallstone composition to the rate of gallstone dissolution in the Rhesus monkey and in man. 9th International Congress of Gastroenterology, Paris 1972. Archives Français des Maladies de l'Appareil Digestif, 6, 172-3.

Cahlin, E., Jönsson, J., Nilsson, S., and Scherstén, T. (1973). Biliary lipid composition in normolipidemic and prebeta hyperlipoproteinemic gallstone patients. Scandinavian Journal of Gastroenterology, 8, 449-456.

Fiske, C. H., and Subbarrow, Y. (1925). The colorimetric determination of phosphorus. Journal of Biological Chemistry, 66, 375-400.

Heller, F., and Bouchier, I. A. D. (1973). Cholesterol and bile salt studies on the bile of patients with cholesterol gallstones. Gut, 14, 83-88.

Leffler, H. H., and McDougald, C. H. (1963). Estimation of cholesterol in serum. American Journal of clinical Pathology, 39, 311-315.

Mackay, C., Crook, J. N., Smith, D. C., and McAllister, 
R. A. (1972). The composition of hepatic and gallbladder bile in patients with gallstones. Gut, 13, 759-762.

Malagelada, J. R., Go, V. L. W., Summerskill, W. H. J., and Gamble, W. S. (1973). Bile acid secretion and biliary bile acid composition altered by cholecystectomy. American Journal of Digestive Diseases, 18, 455-459.

Metzger, A. L., Adler, R. D., Heymsfield, S., and Grundy, S. M. (1973). Diurnal variation in biliary lipid composition. New England Journal of Medicine, 288, 333-336.

Nakayama, F., and Van der Linden, W. (1974). Role of gallbladder in gallstone formation. Acta Chirurgica Scandinavica, 140, 45-49.

Nilsson, S., and Scherstén, T. (1969). Importance of bile acids for phospholipid secretion into human hepatic bile. Gastroenterology, 57, 525-532.

Pedersen, L., Arnfred, T., and Hess Thaysen, E. (1974). Cholesterol kinetics in patients with cholesterol gallstones before and during chenodeoxycholic acid treatment. Scandinavian Journal of Gastroenterology, 9, 787-791.

Redinger, R. N., Herman, A. H., and Small, D. M. (1971). Effect of diet on bile composition in the Rhesus monkey. Gastroenterology, 60, 198.

Scheffé, H. (1959). The Analysis of Variance. Wiley: New York.

Scheffé, H. (1970). Practical solutions of the Behrens-Fisher problem. Journal of the American Statistical Association, 65, 1051-1062.

Scherstén, T.. Cahlin, E., Jönsson, J., Lindblad, L., and Nilsson, S. (1974). Supersaturated bile-is it due to a metabolic disorder or to an impaired gallbladder. Scandinavian Journal of Gastroenterology, 9, 501-506.

Scherstén, T., Nilsson, S., Cahlin, E., Filipson, M., and Brodin-Persson, G. (1971). Relationship between the biliary excretion of bile acids and the excretion of water, lecithin, and cholesterol in man. European Journal of Clinical Investigation, 1, 242-247.

Shaffer, E. A., Braasch, J. W., and Small, D. M. (1972). Bile composition at and after surgery in normal persons and patients with gallstones. New England Journal of Medicine, 287, 1317-1322.

Simmons, F., Ross, A. P. J., and Bouchier, I. A. D. (1972). Alterations in hepatic bile composition after cholecystectomy. Gastroenterology, 63, 466-471.

Small, D. M., and Rapo, S. (1970). Source of abnormal bile in patients with cholesterol gallstones. New England Journal of Medicine, 283, 53-57.

Smallwood, R. A., Jablonski, P., and Watts, J. McK. (1972). Intermittent secretion of abnormal bile in patients with cholesterol gall stones. British Medical Journal, 4, 263-266.

Sutor, D. J., and Wooley, S. E. (1969). X-ray diffraction studies of the composition of gallstones from English and Australian patients. Gut, 10, 681-683.

Sutor, D. J., and Wooley, S. E. (1971). A statistical survey of the composition of gallstones in eight countries. Gut, 12, 55-64.

Talalay, P. (1960). Enzymic analysis of steroid hormones. Methods in Biochemical Analysis, 8, 119-143.

Tera, H. (1960). Stratification of human gallbladder bile in vivo. Acta Chirurgica Scandinavica, Suppl. 256, 1-85.

Van der Linden, W. and Nakayama, F. (1974). Occurrence of cholesterol crystals in human bile. Gut, 15, 630-636.

Vlahcevic, Z. R., Bell, C. C., Jr., Gregory, D. H., Buker, G., Juttijudata, P., and Swell, L. (1972). Relationship of bile acid pool size to the formation of lithogenic bile in female Indians of the southwest. Gastroenterology, 62, 73-83.

Vlahcevic, Z. R., Bell, C. C., Jr., and Swell, L. (1970). Significance of the liver in the production of lithogenic bile in man. Gastroenterology, 59, 62-69. 